\title{
Determinants of the Best Practices for Successful Project Management
}

\author{
Suliman Saleh Al Freidi \\ Al-Qassim University, Buraidah City \\ salfreidi@gdpm.qu.edu.sa
}

\begin{abstract}
Engineers and Architects are expected to perform a variety of tasks depending on their specialization and job level. Some features of the construction industry, has been the use of project management (PM.) concept of building procurement. The PM approach has proved its success in certain types of projects. This paper presents the causes of success of the PM technique in engineering projects. The result was obtained from the views different client organizations, project managers, design consultants and contractors, as to what determines project success. One of the interesting insights of the study suggest that the project manager risk management, running start, multi-level project governance, interoperability standard maintenance, internal and external project management, policy and technical project management, project planning, monitoring, and communications, solution sustainability, and education agency acceptance were among the highly rated determinants that determine the success of PM projects. The aim is to show the determinants that are associated with outstanding, average and familiar projects.
\end{abstract}

Keywords: Managing projects, project management, project phases, project success

\section{Introduction}

The current design and construction spree in the country of Saudi Arabia produced buildings as tall as 50 stories, buildings with six basements levels, roads, infrastructures, airports and seaports costing billions of riyals. Just like any other important project management of a particular project needs vision and guidelines in order for it to be carried out effectively. As currently practiced in the industry, the best practices for successful project management varies from different companies or from one professional to another. Notwithstanding the variances of the scope or nature of the project management services, the following planning concerns could serve as a bottom line or reference point.

In Advanced Pipeline System of Auckland City, the Project Manager supervises and monitors the progress of a project. For ethical and responsibility reason, the Project Manager and Construction Manager should not directly supervise the contractor's staff, laborers, subcontractors, and suppliers $[1,12]$.

The Project Manager normally coordinates directly with the Owner, the designer of the project and Construction Manager. The Construction Manager monitors or supervises the construction activities of the contractor and its subcontractors, and also the delivery of suppliers by the suppliers.

When the project is small, the Project Managers and the Construction Manager could be one person. If the project is large or needs to be done over a long period of time, say more than two years, the Project Manager is a separate person from a Construction Manager. As 
practiced in Saudi Arabia, the Construction Manager is also known as either the Owner's Representative, or the Resident engineer.

When monitoring or supervising a particular project, three definitive concerns should be considered [1,5]. These concerns are: (a) planning; (b) execution; and (c) reporting/recording.

The Project Manager should map out strategies with and delegate some of the concerns to the Construction Manager so that the planning objectives of the project are identified and shared between them. The Project Manager should initiate the mapping out of the strategies within two or four weeks after the start of the project, preparation should be prepared. The Project Manager should sustain the mapping out and update the strategies regularly, say every six months, with inputs obtained from the Owner, the designer, the Construction Manager, and the contractor. The Project Manager is the contact person between the project proponent (client as owner) on the hand, and the consulting company (or practitioner) hired by the owner to perform the Construction Management, on the other.

Moreover, PM techniques also plays major role in the efficient and effective development of new technology and systems [8]. Project management success is measured by criteria which mean different things to different people depending upon their role within the project itself $[8,14]$. It often changes from project to project depending on participants, scope of services, project size, owner design of facilities, technology implications and a variety of other factors. On the other hand, common threads relating to success criteria often develop not only within an individual project, but across the industry, as it relate success to the perceptions and expectations of the client, project manager, designer or contractor.

\section{Literature Review}

\subsection{Service management framework}

The Service Management Framework (SMF) is the overarching management bestpractice framework that provides the foundation for the UPMM. The SMF provides a set of processes and procedures that are efficient, reliable and adaptable to meet the needs of the full project lifecycle through strategy (portfolio and program management), tactical (project management) and operational levels (facility management, maintenance and service delivery) [2,3]. In the modern world the concept of having a strategy to drive a business forward with adequate planning and design transitioning into day-today operation is compelling. In this ever-changing world the provision of a clear and precise strategy that aligns the business requirements with the service provider, ensuring that the service provider becomes a strategic partner, has never been more important. The principles contained within SMF have been proven countless times in the real world and are based on international best practice in service provision. The practice of continual service improvement is one of the cornerstones of the SMF.

2.1.1. Strategic level: The strategic level of the SMF is concerned with value creation and begins with understanding organizational objectives and customer needs. It is at this level that the SMF supports the UPMM's Portfolio Management and Program Management methodologies. The strategic level of the SMF provides guidance on how to view service management not only as an organizational capability but as a strategic asset. It describes the principles underpinning the practice of service management which are useful for developing service management policies, guidelines and processes all levels of the SMF. This level of the SMF is about ensuring that any business is in a position to handle the costs and risks associated with their portfolio, and are set up not just for operational effectiveness but for 
distinctive performance. This level will assist the business to stop and think about why something is to be done before thinking of how.

Figure 1 shows the processes within the strategy lifecycle of the SMF [2].

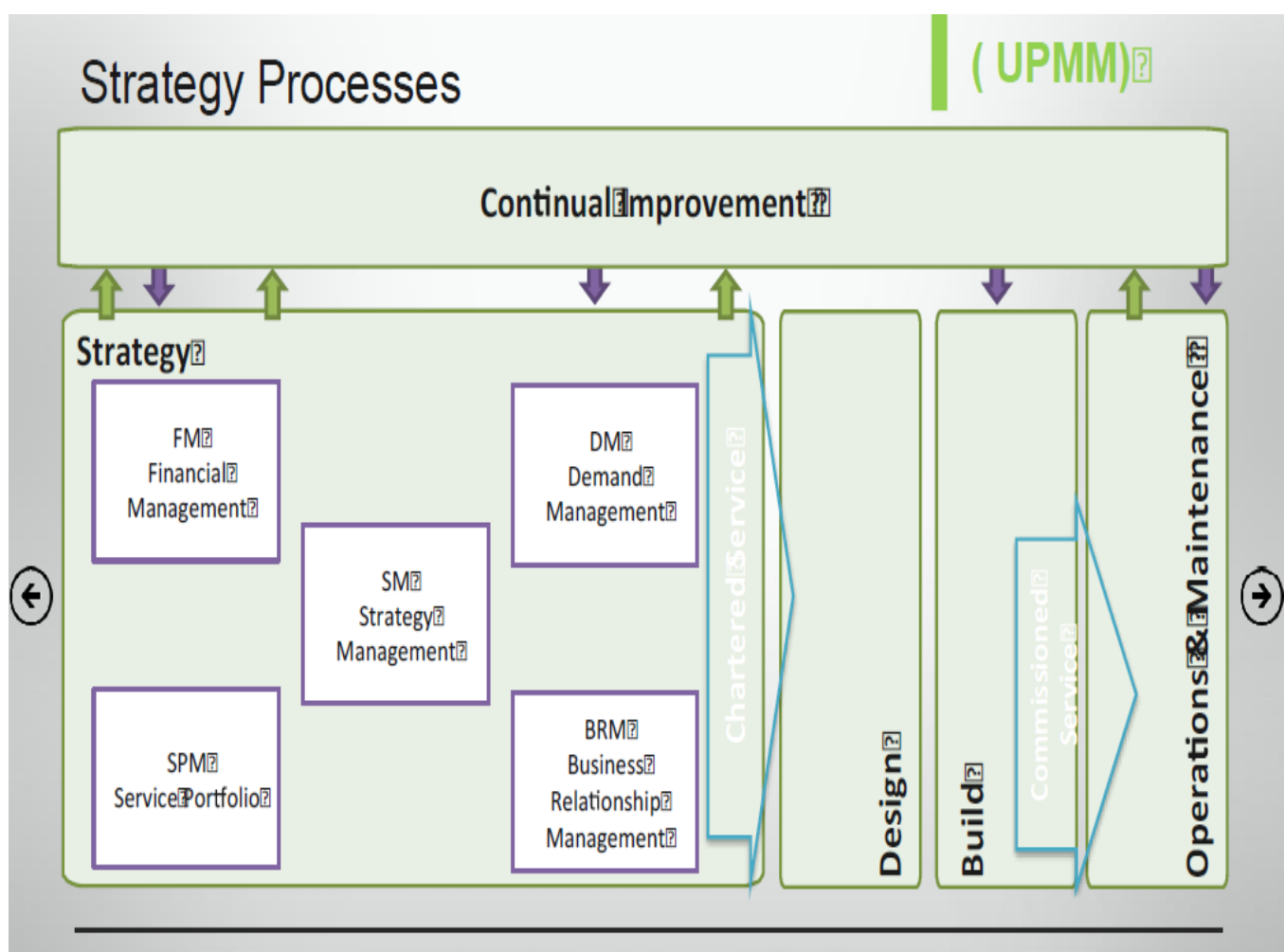

Figure 1. Strategy Lifecycle of the SMF

2.1.2. Tactical Level: The tactical level of the SMF describes best practice for designing and transitioning (building) services into supported environments. This level of the SMF has a direct relationship with the UPMM project delivery. For services to provide true value to the business, they must be designed with the business objectives in mind. The tactical level of the SMF turns the service strategy into a plan for delivering the business objectives. The tactical level provides guidance for the design and development of services and service management practices. It covers design principles and methods for converting strategic objectives into portfolios of services and service assets. The tactical level also provides guidance for the development and improvement of capabilities for introducing new and changed services into supported environments while providing guidance on managing the complexity related to changes to services and service management processes, preventing undesired consequences while allowing for innovation. This level also introduces the knowledge management system, which can support organizational learning and help to improve the overall efficiency and effectiveness of program and project delivery as well as operations and maintenance. This will enable people to benefit from the knowledge and experience of others, support informed decision-making, and improve the management of services.

Figure 2 shows the processes within the design lifecycle of the SMF and Figure 3 shows the processes within the build lifecycle of the SMF [2]. 


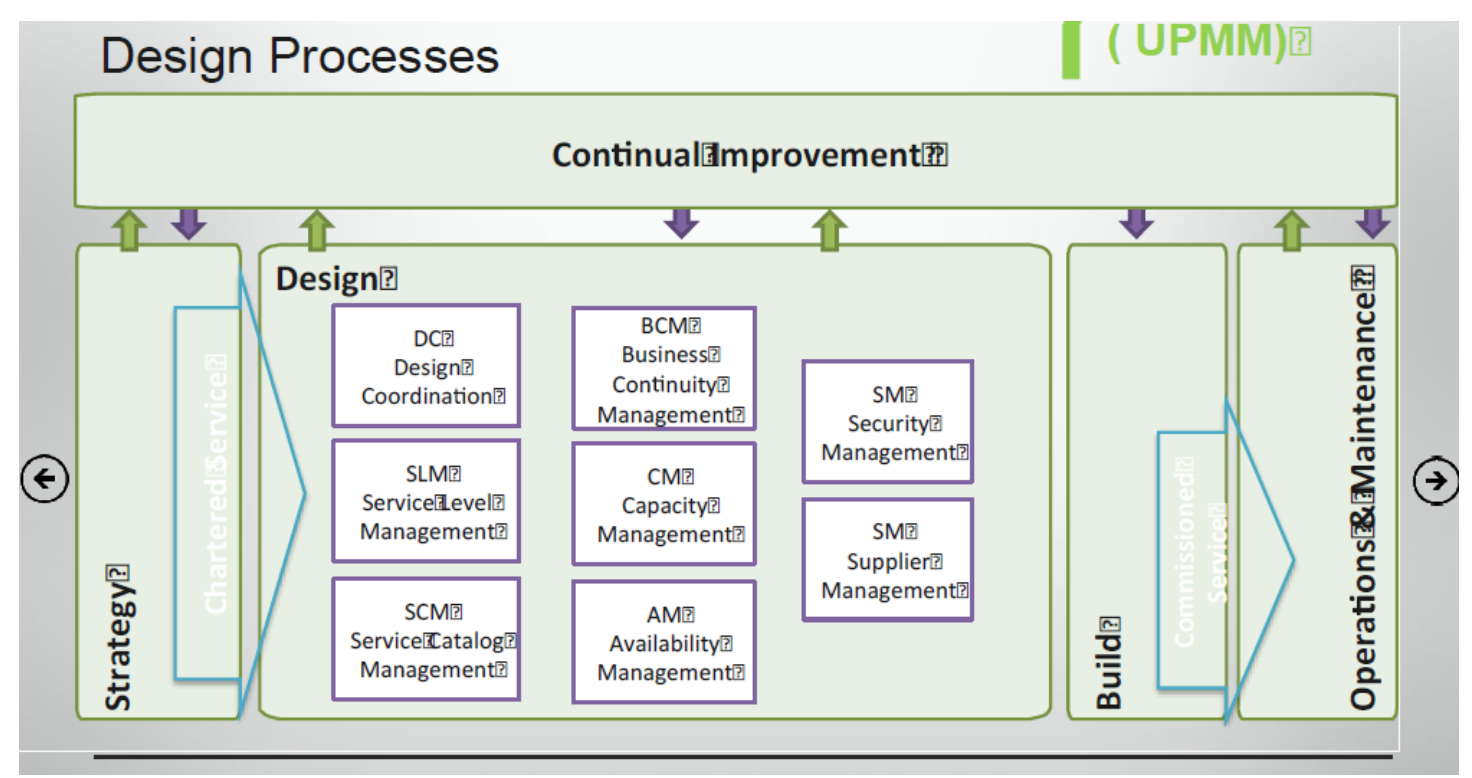

Figure 2. Design Lifecycle of the SMF

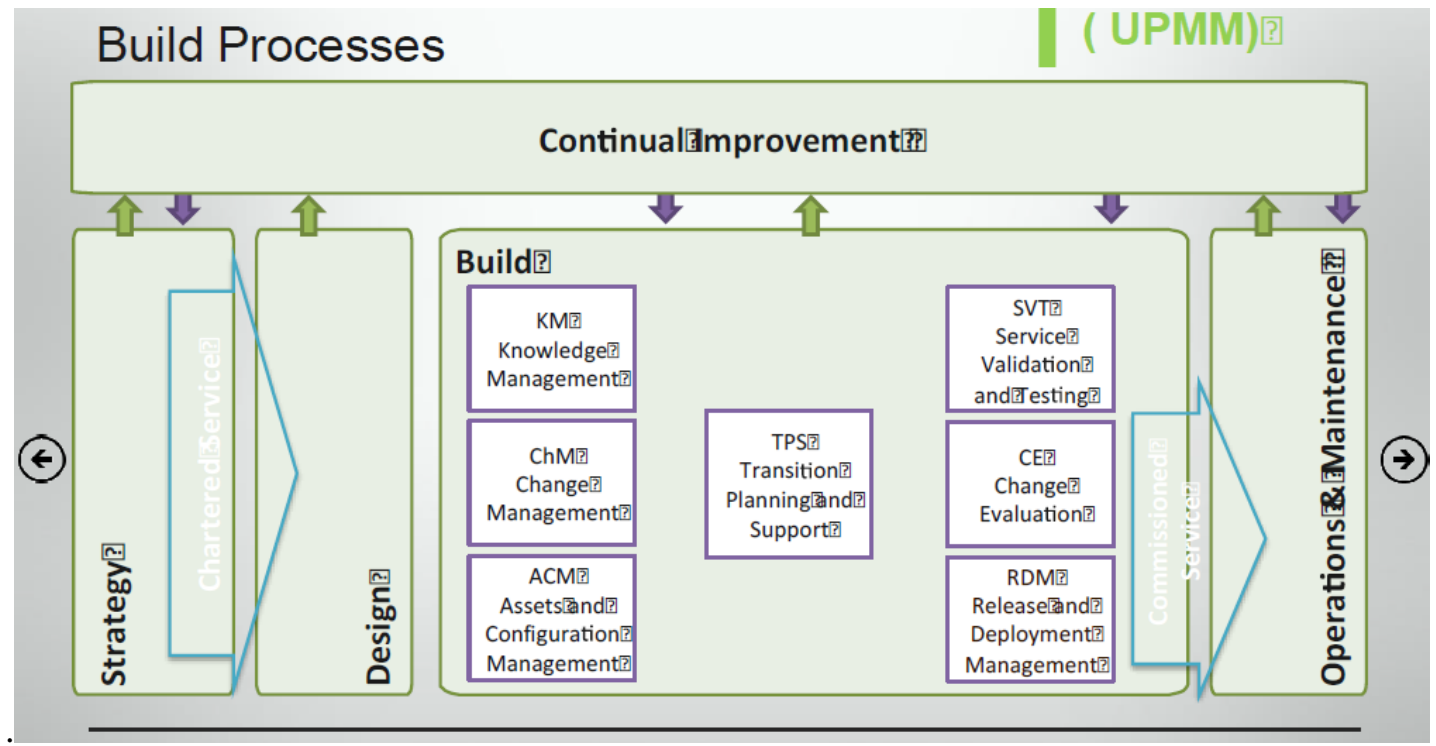

Figure 3. Build Lifecycle of the SMF

2.1.3. Operational Level: The Operational level of the SMF describes best practice for managing services in supported environments. It includes guidance on achieving effectiveness and efficiency in the delivery and support of services to ensure value for the customer, the users and the service provider. Strategic objectives are ultimately realized through service operation, therefore making it a critical capability for any service provider. The Operations level provides guidance on how to maintain stability in service operation, allowing for changes in design, scale, scope and service levels. The UPMM will provide detailed process guidelines, methods and tools for use in two major control perspectives: reactive and proactive. This will allow the service provider within the UPMM with knowledge allowing them to make better decisions in areas such as managing the availability 
of services, controlling demand, optimizing capacity utilization, scheduling of operations, and avoiding or resolving service incidents and managing problems.

Figure 4 shows the processes within the operations lifecycle of the SMF [2].

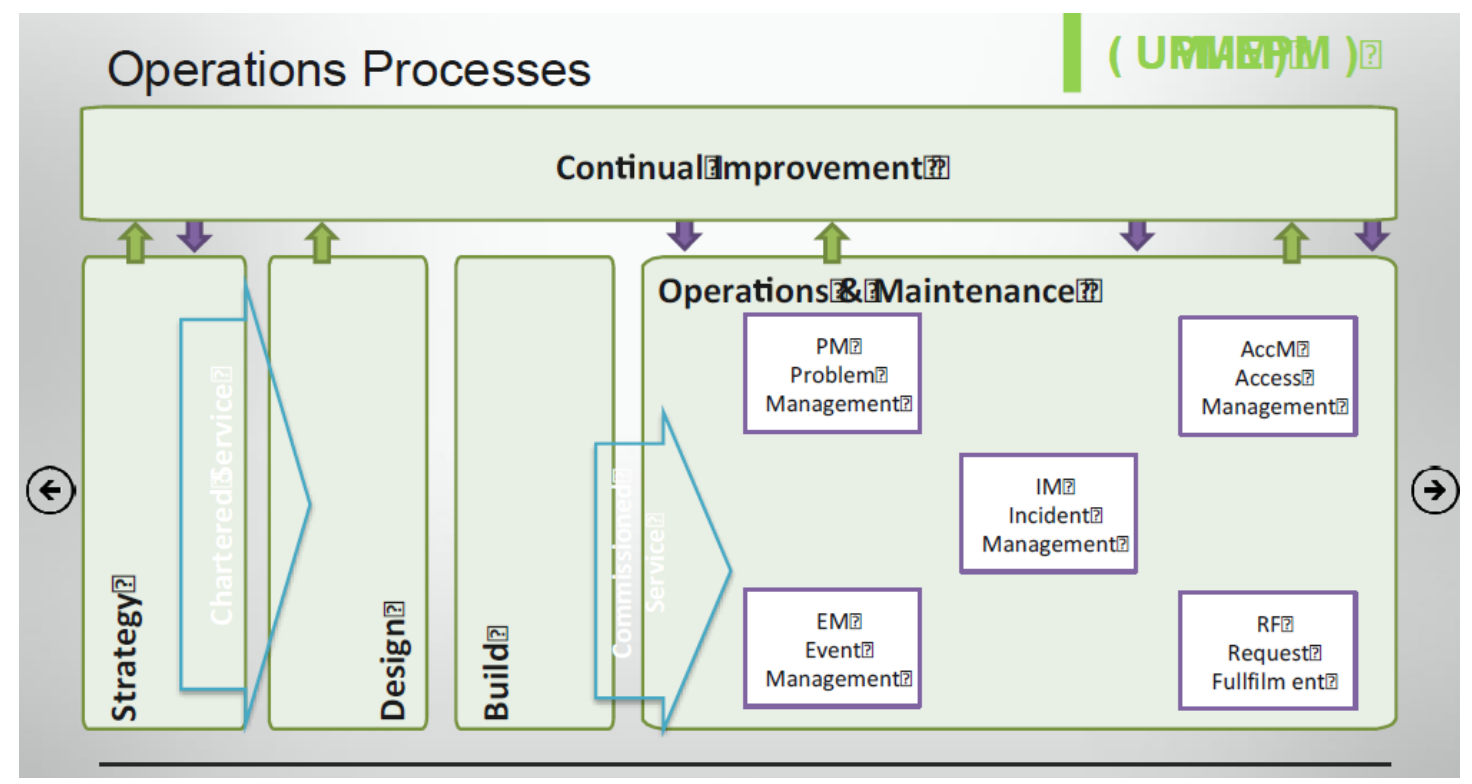

Figure 4. Operational Lifecycle of the SMF

\subsection{Portfolio, programs and project office (p3o)}

2.2.1. Management of portfolios (MoP): Organizations are much more cautious with their investments these days. Organizations need to answer the following questions for initiatives within projects and programs: (a) Can we afford this?, (b) Can we take the risk? \& (c) Should we be doing this? As such, the days of projects being funded without having a clear understanding of the full costs, benefits and risk are well and truly behind us. MoP helps organizations answer a fundamental question 'Are we sure this investment is right for us and how will it contribute to our strategic objectives?' Investment is the keyword because portfolio management is about investing in the right business initiatives and implementing them correctly [2, 4]. MoP achieves this by ensuring that: (a) The programs and projects undertaken are prioritized in terms of their contribution to the organization's strategic objectives and overall level of risk. (b) Programs and projects are managed consistently to ensure efficient and effective delivery. (c) Benefits realization is maximized to provide the greatest return (in terms of strategic contribution and efficiency savings) from the investment made. Projects (and to a lesser extent programs) have been the focus of organizations' efforts to manage change for many years. More recently, portfolio management has come to the fore as organizations have become increasingly aware that delivery is only half the battle. Just as important are whether or not the change initiatives are the 'right' ones and whether the potential return on investment is achieved. Understanding which change initiatives contribute most to an organizations strategy is both complex and difficult; furthermore making informed decisions about their overall status, prioritization, risk 
and benefits is even more difficult. MoP provides a solution to such difficulties. It does not mandate specifically how organizations should use portfolio management; it would be futile to do so because every organization is so different. However, it does provide a picture of success and defines the principles and practices that have been used by organizations to achieve that success. MoP helps organizations to use Best Practice to manage projects, programs and services consistently and effectively. MoP focuses on strategic investment decision-making and integrates seamlessly with all other best practice methodologies. It is highlighted throughout MoP that portfolio management will be more effective where robust program and project management (PPM) exists [2, 4].

2.2.2. Managing successful programs: Managing Successful Program (MSP) is a bestpractice framework for delivering complex programs in accordance with long-term strategies. MSP was developed for and is owned by the Office of Government Commerce (OGC), an agency of the Government of the United Kingdom. MSP was released in recognition of the need for greater links between an organization's longer-term strategy, objectives and goals and the projects being undertaken by that organization. MSP defines program management as 'the action of carrying out the coordinated organization, direction and implementation of a dossier and transformation activities to achieve outcomes and realize benefits of strategic importance to the business. Organizations need to have a reasonable level of project management maturity to enable the program management framework to be efficiently applied [13]. Organizations in this position are often interested in applying a more holistic approach to their work which is more focused on stakeholder engagement and benefits management. MSP is a pragmatic approach to program management which ensures that a strong leadership and governance structure is established and maintained [13]. There is a strong emphasis placed on stakeholder engagement and benefits realization management. MSP ensures that these areas receive the focus required to ensure change occurs and benefits are generated. The benefits of adopting a recognized approach are primarily that all programs will be managed in the same way - utilizing best-practice. This will raise the visibility of all aspects of the program and enable the assurance and governance functions to operate effectively.

2.2.3. Transformational flow: The term 'transformational flow' is used to describe a series of six processes which guide the program management team through the program. Each process details the management activities that are required to be undertaken at each step of the program [7]. The transformational flow is designed to ensure that the team gathers information and makes decisions at the appropriate point in the program's lifecycle

2.2.4. PRINCE2 and PMBOK: The Project Management Institute Guide to Project Management (PMBOK) is a widely accepted statement of the sum of knowledge within the profession of project management, and has been adopted by many organizations as the basis for their project management specialist. The PMBOK originates from the USA [2, 6]. PRINCE2 is leading project management methodology, aiming to provide mechanism for the setting up of a framework within which to run a project, the running of that project and its closure with handover to 
operational areas [6]. PRINCE2 was developed for and is owned by the Office of Government Commerce (OGC), an agency of the Government of the United Kingdom. Note that the PMBOK is a standard, not a project management methodology. To successfully apply the PMBOK standard organizations need to manage projects using a robust methodology such as PRINCE2. These two project management approaches should not be seen as mutually exclusive; instead they can be seen to complement each other [6]. There is a high level of compatibility between the two approaches to project management. Broadly speaking, PMBOK is specifying the detailed techniques which need to be addressed in project management, and as such identifying the processes and procedures which need to be put in place. PRINCE2, being a methodology, is offering the processes and procedures to control projects [2,6]. The adoption of PRINCE2 enhances the implementation of the PMBOK standards by providing greater depth and structure to the establishment of project environments, and by providing a more rigorous approach to the setting up, running and closing down of individual projects. Also the adoption of the PMBOK to a PRINCE2 based organization will help to identify the additional areas which need to be addressed in order to give projects the best chance of success, such as soft skills and procurement [2,6]. Both approaches should not be viewed as competing against each other but to complement the strengths and weaknesses of both knowledge and processes. Organizations may find the benefits to allow both methods to co-exist and apply them in a systematic yet creative ways. By using both PRINCE2 and PMBOK, the UPMM will be using the best project management approaches from both worlds.

\subsection{Managing Organizational Change}

Change Management as a best practice should not be seen as prescriptive. A 'onesize-fits all' approach to managing change is ineffective, as each organization is different, with its own structure, history, culture and needs, and each change event is different. The characteristics of each change (type, breadth, size, origin etc.) also influence the way change is planned and effectively managed. Despite the range of approaches to change management, some common factors for delivering successful change exist. These factors apply across all large and complex organizations [13].

\subsection{Managing Organizational Change}

The American Institute of Architects (AIA) is a professional organization for architects in the United States. The AIA offers education, government advocacy, community redevelopment, and public outreach to support the architecture profession and improve its public image. The AIA also works with other members of the design and construction team to help coordinate the building industry.

\subsection{American Institute of Architects' Framework}

The American Institute of Architects (AIA) is a professional organization for architects in the United States [2, 9]. The AIA offers education, government advocacy, community redevelopment, and public outreach to support the architecture profession and improve its public image [9]. The AIA also works with 
other members of the design and construction team to help coordinate the building industry.

\subsection{Construction Specifications Institute Framework}

The Construction Specifications Institute (CSI) is an organization that maintains and advances the standardization of construction language as pertains to building specifications. CSI authored Master-Format, which is an indexing system for organizing construction data, particularly construction specifications $[12,10]$. In November 2004, Master-Format was expanded to 50 Divisions, reflecting the growing complexity of the construction industry, as well as the need to incorporate facility life cycle and maintenance information into the building knowledge base $[10,13]$. In this way, Master-Format will eventually help facilitate Building Information Modeling (BIM) to contain project specifications. Master-Format helps architects, engineers, owners, contractors, and manufacturers classify how various products are typically used.

\subsection{GIS (Geographic Information Systems)}

As in this heading, they should be Times New Roman 11-point boldface, initially capitalized, flush left, with one blank line before, and one after. A geographic information system (GIS) integrates hardware, software, and data for capturing, managing, analyzing, and displaying all forms of geographically referenced information. Implementing a GIS allows us to view, understand, question, interpret, and visualize data in many ways that reveal relationships, patterns, and trends in the form of maps, globes, reports, and charts $[10,11]$. A GIS helps answer questions and solve problems by looking at data in a way that is quickly understood and easily shared.

GIS benefits organizations of all sizes and in almost every industry. There is a growing awareness of the economic and strategic value of GIS.

\section{Quality Project Methodology (QPM) Best Practice Characteristics}

Project Managers want to work with a project management integrator who they can trust, who understands them and their needs, and who is on their side. Inherent in QPM is the knowledge that projects and project managers must be attentive to the needs of stakeholderdriven organizations, in contrast to businesses, which are shareholder-driven. This means that the industry-standard project management methodologies fall short in delivering the results required of education agencies The QPM methodology incorporates and emphasizes the differences of construction companies among all types of organizations, as well as the uniqueness of each agency among other construction companies.

Figure 5 illustrates the best practice characteristics of QPM. The characteristics of QPM that exemplify the researcher approach [14-16]: 


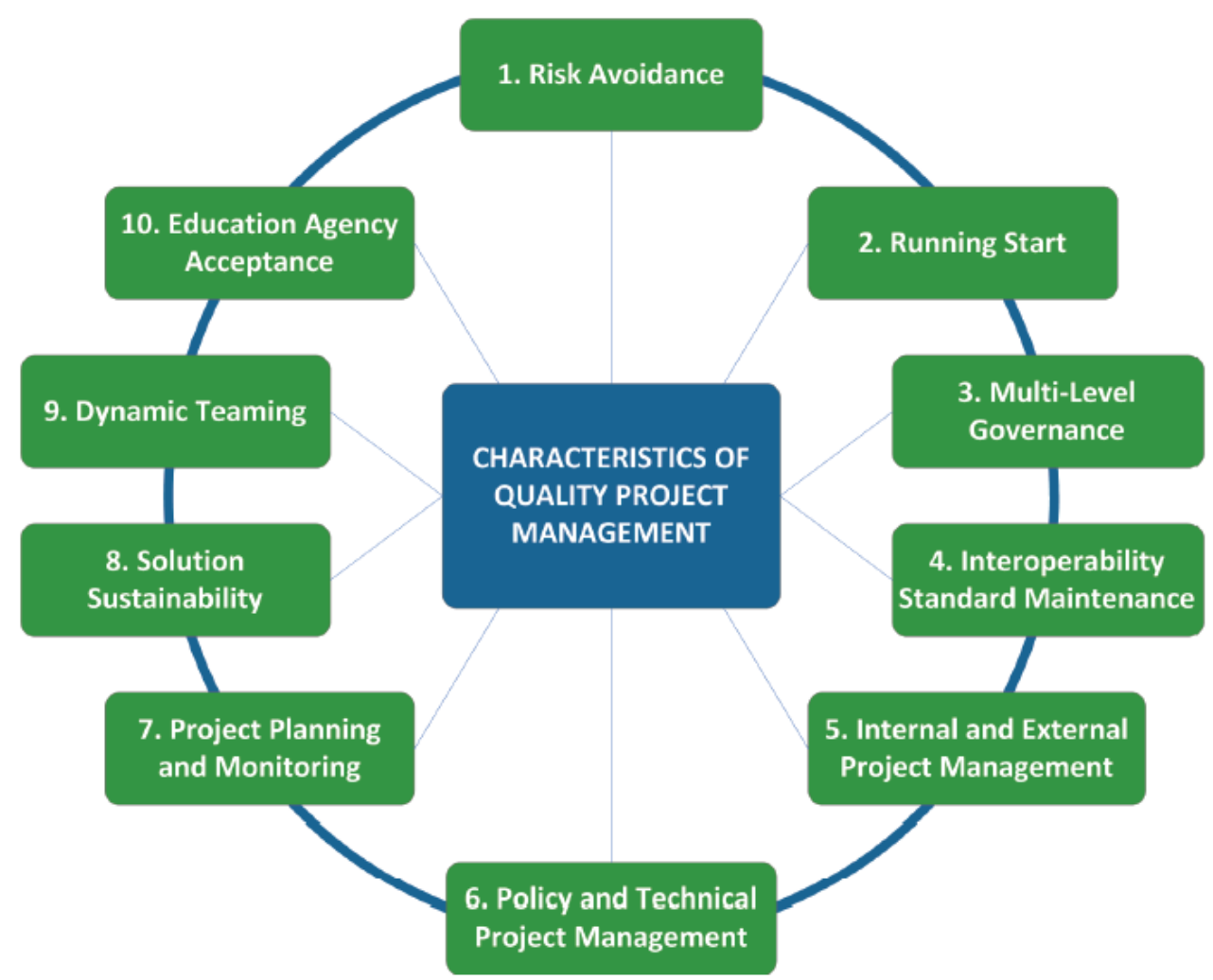

Figure 5. Characteristics of Quality Project Management

\subsection{Risk management}

Document and mitigate project risk by utilizing QPM's proven risk management methodology that identifies risk factors up front and continues to track them throughout the project lifecycle

\subsection{Running start}

Use proven project planning techniques, QPM and policy document templates, and management processes to mitigate the typical slow start-up of major projects.

\subsection{Multi-level project governance}

Rely upon oversight and advice from key stakeholder groups. Continual and effective communications within and across the following groups is a key success factor.

\subsection{Interoperability standard maintenance}

Ensure interoperability of all components of the proposed information solution to manage redundancy, conflicts, and burden on construction companies and other staff 


\subsection{Internal and external project management}

Coordinate the project management activities with the education agency project managers and those contracted through external vendors. Ensure coordination and partnership with a mutually agreed upon, consolidated project management plan.

\subsection{Policy and technical project management}

Align both the construction companies technical and policy components of project management to ensure that implementation is smooth. Team the construction companies' staff with vendor architects and technical experts to combine expertise.

\subsection{Project planning, monitoring, and communications}

Use professional project management tools to document and monitor the project's plan. Adhere to a disciplined program of both regularly scheduled and ad-hoc internal and external project status/technical status meetings. Project planning, monitoring, and communications processes are strictly followed as part of the project's management infrastructure. Change management best practice is also closely followed

\subsection{Solution sustainability}

Ensure that the chosen solution is going to be effective in the long-term by aligning the issues and needs of the stakeholders with the features and functions of the applications, products, and processes implemented.

\subsection{Dynamic teaming}

Response to changing project contexts and needs via strategy of moving key staff into and around management responsibilities to meet the demands of the project allows for implementation to progress while maintaining oversight and continuity. This also provides construction companies breadth of expertise that spans both the political and technical landscape to the construction industry.

\subsection{Construction industry acceptance}

Ensure the quality and functionality of each deliverable in the project management plan by following a collaborative, prescribed process for quality assurance and construction industry acceptance. Follow rigorous user acceptance testing before signing off on the implementation of each project component.

The following figures provide examples as to what resources are pulled in and when, what their responsibilities are, and how intense their involvement is in each phase throughout the project lifecycle. The figures illustrate QPM resource involvement and the strategy of moving in key staff and management responsibilities to match the demands of the project as implementation progress.

Figure illustrates levels of effort over time. The figure also speaks to the roles of the project executive, project director, and project manager, over the course of the project lifecycle (from left to right), and the activities in which they are involved [5, 13]. 


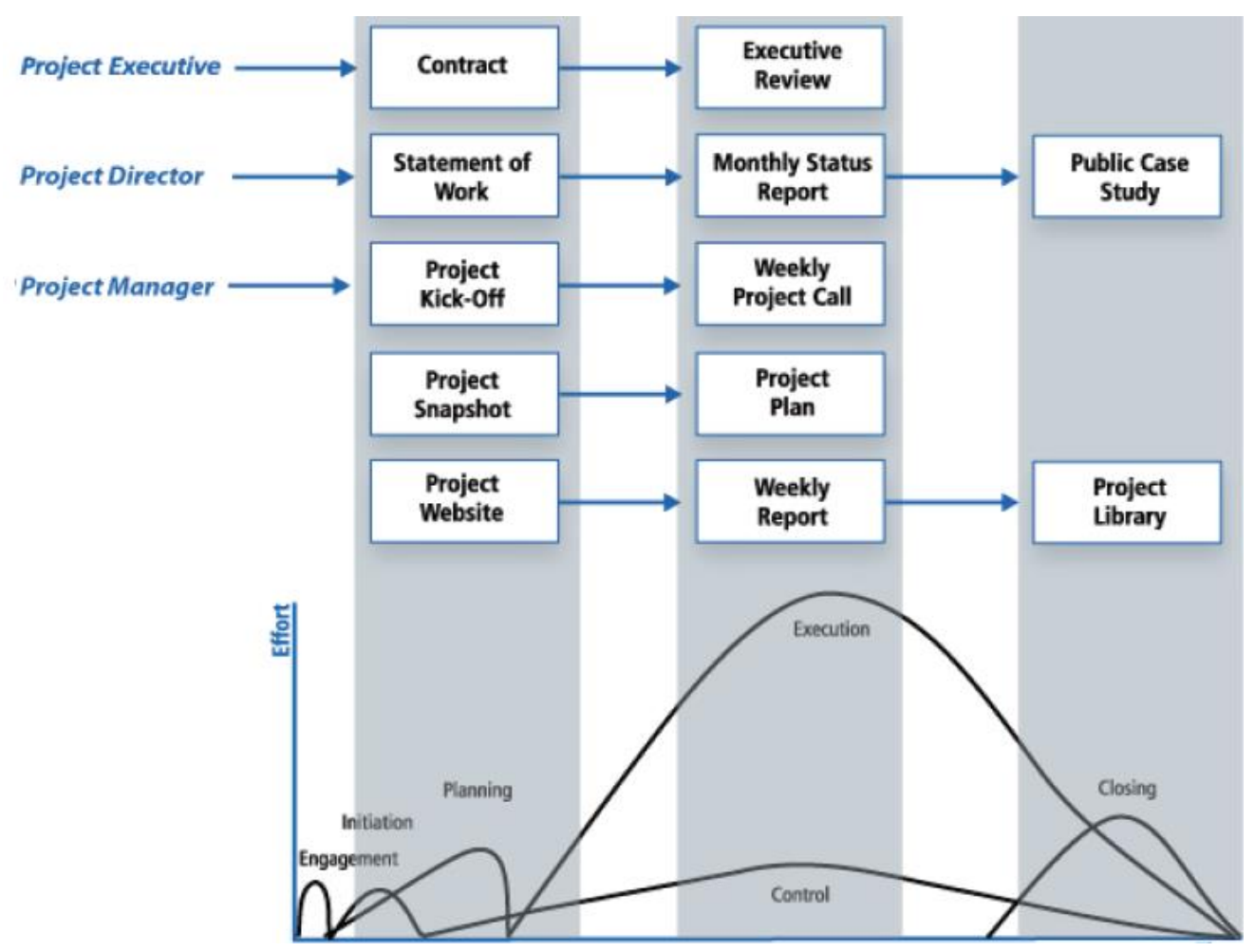

Figure 6. QPM methodology - Roles and Project Lifecycle

Figure 7 illustrates the resources and roles that are instrumental to each of the QPM project management processes, mapped to the levels of involvement during the various phases of the QPM project lifecycle [5, 13].

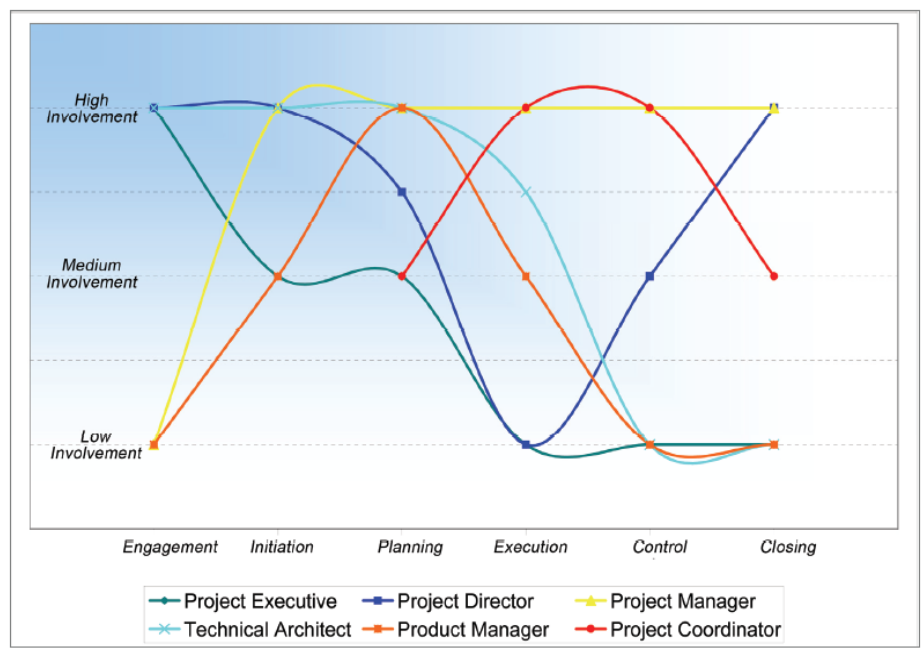

Figure 7. QPM role to Stage Mapping for Project Management Processes

Figure 8 illustrates the roles that are instrumental to successful project execution, mapped to levels of involvement during the phases of the QPM project lifecycle [5, 13]. 


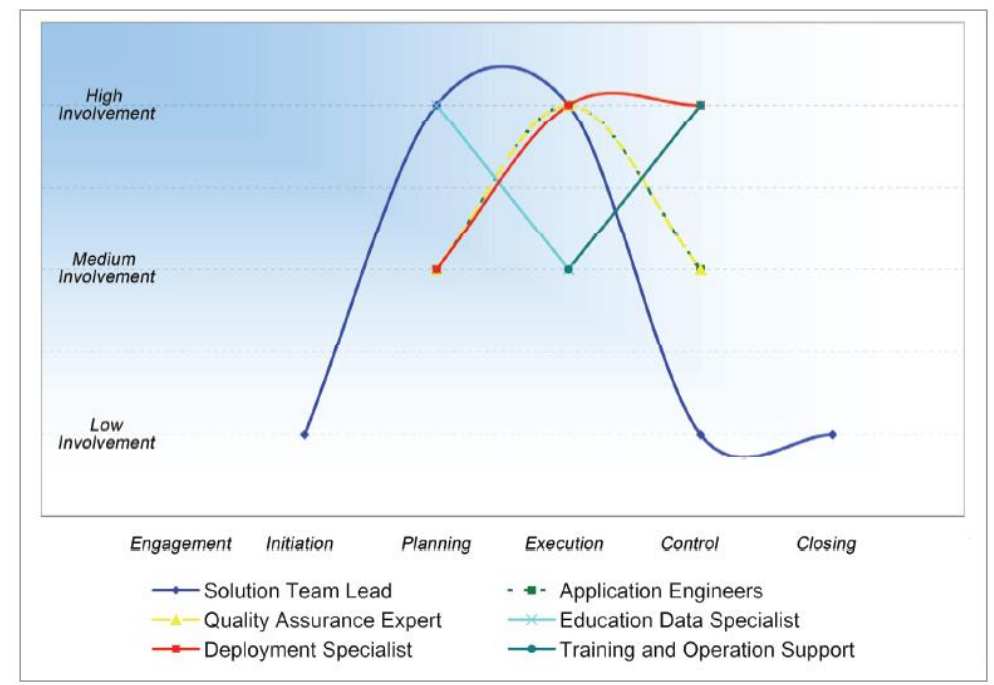

Figure 8. QPM Role to Stage Mapping for Successful Project Execution

\section{Conclusion}

Literature reviews in the field of project management generate lists of critical success determinants, each of which varies in its scope and purpose. In this study, the researcher intended to classify the determinants of project management success and explain the interaction between them, rather than the identification of individual determinants. This research aims to identify the determinants best practices for successful project management based from the views different client organizations, project managers, design consultants and contractors. The determinants were risk management, running start, multi-level project governance, interoperability standard maintenance, internal and external project management, policy and technical project management, project planning, monitoring, and communications, solution sustainability, and education agency acceptance. Project managers managerial experience' is viable and can be as critical as the organizational and the project system determinants. With this regard, the determinants classified under the project system heading can be crucial in determining success, in particular, 'scope and work definitions'. It can be concluded, therefore, that investigating determinants of project management success is a fertile area to pursue on a much larger scale. It is established that not only what determinants are important for achieving an outstanding project result, but also how they are interrelated and influence the project management success.

\section{References}

[1] T. U. Ganiron Jr, S. Alyahya and A. M. Toumi, "Handouts in GE 402 Course (Project Management)", Qassim University, (2013).

[2] S. Al-Freidi, "Unified Project Management Methodology", Ph.D. Thesis, Faculty of Engineering, Cairo University, Giza, (2013).

[3] R. Sargean, "Creating Value in Project Management using PRINCE2", Queensland University of Technology, Queensland, (2010).

[4] J. Fisher, "Refreshing Management of Risk: Guidance for Practitioners" TSO and John Fisher, UnconfuseU, (2010).

[5] T Ucol-Ganiron Jr and T Malvecino-Ganiron, “ Managing Career Success of Geodetic Engineers", International Journal of Education and Learning, vol 2, no. 1, (2013), pp. 13-24. 
[6] "Comparing the Differences and Complementary features of PRINCE2® and the PMI PMBOK®" Guide, ESI International, (2009).

[7] D. Rainey, "Inventing the Future Through Strategy, Innovation, and Leadership", American Scientific Publishers, Los Angeles, (2009).

[8] T.U. Ganiron Jr, L. Estiller, M. Aguirre, R. Bunag and R. Gallardo, "Technical Guidelines in the Design and Construction of Subdivision in Up-Land Area in Antipolo, Rizal”, BS Thesis, Civil Engineering Department, FEATI University, Manila, (2003).

[9] S. Sahibudin, "Centre Combining ITIL, COBIT and ISO/IEC 27002 in Order to Design a Comprehensive IT Framework in Organizations" University of Teknol, Malaysia, (2010).

[10] "TOGAFTM 9 and ITIL ${ }^{\circledR}$ V3 Two Frameworks Whitepaper", Tom van Sante and Jeroen Ermers Consulting, (2009).

[11] T. U. Ganiron Jr, "Predictors of Career Success of Structural Engineers towards Designing a Career Planning Model", SOPHIA, vol. 21A, (2007), pp. 19-26.

[12] "Strategy Deployment through Portfolio Management: A Risk-based Approach", Ernst \& Young Ltd., (2010).

[13] "Advanced Pipeline System", Onehunga, Auckland, http://www.advancedpipeline.com/, (2009).

[14] S. Millar, "Managing Organizations in New Zealand", Pearson Education, (2006)

[15] T Ucol-Ganiron Jr and T Malvecino-Ganiron, "Social Capital on Civil Engineer Career Success", International Journal of Innovation, Management and Technology, vol 3, no 6, (2012), pp. 718-724.

[16] T. Ganiron Jr, T. Ganiron 111 and N. Ucol-Ganiron, "Modeling the Level of Objective \& Subjective Career Success of Civil Engineers Towards Developing a Career Planning Program”, Proceedings of the 2012 International Conference on Information and Knowledge Management, (2012); Singapore.

\section{Author}

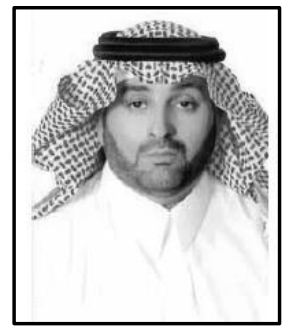

Suliman Saleh Al Freidi. This author was born in the Kingdom of Saudi Arabia. He is a candidate in the degree of Doctor of Philosophy in Architecture Science and Building Technology at the Cairo University (2013). Mr. Freidi was a practitioner in the field of building management, construction management and architectural technology in the provinces of KSA. 
International Journal of $u-$ and e- Service, Science and Technology Vol.7, No.3 (2014) 